\title{
Mechanical ventilation practice in Egyptian pediatric intensive care units
}

\author{
Bassant Salah Meligy $^{1}$, Sally Kamal ${ }^{1}$, Seham Awad El Sherbini ${ }^{2}$
}

${ }^{1}$ MD, Lecturer, Department of Pediatrics, Faculty of Medicine, Cairo University, Cairo, Egypt

${ }^{2}$ MD, Associate Professor, Department of Pediatrics, Faculty of Medicine, Cairo University, Cairo, Egypt

\section{Type of article: Original}

\begin{abstract}
Introduction: Mechanical ventilation is one of the indispensable tools in pediatric intensive care units. Few studies addressed the epidemiology of pediatric patients on mechanical ventilation and the frequently used modes of ventilation. This is the first study to describe the practice of mechanical ventilation (MV) in Egyptian pediatric intensive care units (PICUs).

Methods: This prospective observational study was conducted from January 2014 to December 2014 in two pediatric intensive care units at Cairo University Pediatric Hospital. The study included all children who were intubated and mechanically ventilated for more than 12 hours of admission. Pre-coded data was entered into the SPSS version 21 for data analysis. Comparison between groups was performed using Mann Whitney test for quantitative variables and Chi square with Fisher's exact test for qualitative ones. Multivariate logistic regression model was conducted to explore the significant predictors for PICU mortality.

Results: In total, 893 children were admitted and 293 were mechanically ventilated. The incidence of utilizing MV in children was $32.8 \%$. Neurologic causes were the most common reasons for initiation of MV, with 114 (38.9\%) cases. The most commonly preferred mode for initiation of MV is SIMV with PS. Complication occurred in 117 (39.9\%) of the cases. The most commonly preferred method of weaning was PS with CPAP in $115 / 154(74.7 \%)$ cases. Mortality occurred in 134/293 (45.7\%) of patients. Duration of mechanical ventilation was significantly longer with neuromuscular diseases, and with the occurrence of complications $(p<0.001)$. There was a significant relationship between mortality and higher PRISM III score, cardiovascular cases, sepsis, multiple organ dysfunction syndrome (MODS), ventilator-associated pneumonia (VAP), and with barotrauma.

Conclusions: In our practice, MV is used oftentimes with almost a third of admissions requiring intubation for different reasons. Most children are ventilated due to neurologic causes. This study paves the way for improving our knowledge of MV with avoiding the fatal complications.
\end{abstract}

Keywords: Mechanical Ventilation, Pediatric, Prognosis, Mortality, Respiratory Failure

\section{Introduction}

Mechanical ventilation (MV) in PICU is a major therapeutic modality, and a major indication for PICU admission. The frequency of utilizing MV, according to previous studies, varies from $24-60 \%$ of all pediatric intensive care units (PICUs) (1-4). Two multicenter studies, the International Group for Mechanical Ventilation in Children (IGMVC) and the Pediatric Acute Lung Injury and Sepsis Investigators (PALISI) have studied characteristics of pediatric patients on MV $(6,7)$. Pediatric patients on MV are the severest of cases requiring PICU admission. MV is employed for a variety of reasons and with different modes and variable outcomes. The extended knowledge of MV is valuable in various aspects; optimizing its use in critically sick children, and allocation of hospital resources as utilization rate determines the needed number of PICU beds (5). To our knowledge this is the first study to describe the characteristics of pediatric patients on MV in our country, which is important in intensifying training for its use and avoiding lethal complications. Our study aimed at assessing the reasons for using MV, clinical spectrum,

\section{Corresponding author:}

Dr. Bassant Salah Meligy, Department of Pediatrics, Faculty of Medicine, Cairo University, Cairo, Egypt.

Tel: +20.1142588882, Email: basantsalah2003@yahoo.com

Received: August 02, 2016, Accepted: September 11, 2016, Published: May 2017

iThenticate screening: September 11, 2016, English editing: April 02, 2017, Quality control: May 02, 2017

(C) 2017 The Authors. This is an open access article under the terms of the Creative Commons Attribution-NonCommercialNoDerivs License, which permits use and distribution in any medium, provided the original work is properly cited, the use is non-commercial and no modifications or adaptations are made. 
different modes of ventilation, complications rate, risk factors of mortality and prognosis of sick children on MV in a Middle Eastern country.

\section{Material and Methods}

\subsection{Design and setting}

In this observational study, we prospectively followed the pediatric patients who were admitted to intensive care, at Cairo University Pediatric Hospital from January 2014 to December 2014, as two separate general intensive care units with 24 beds and 24 ventilators allocated to each bed collectively.

\subsection{Instruments and procedures}

The mechanical ventilators which were available for this study were Newport 360E. Inclusion criteria were; children aged between 1 month to 18 years, and intubation for more than 12 hours. Subjects were excluded if they were intubated for less than 12 hours, neonates, and post-operative cardiothoracic patients. Hypoxemia was defined as $\mathrm{PaO}_{2}<50$ and hypercapnia was defined as $\mathrm{PaCO}_{2}>50 \mathrm{mmHg}$. Subjects' data were collected including demographic data as age and sex, diagnosis, reason for initiation of MV, PRISM III, length of stay on MV from the time of initiation to the time of liberation, mode of MV used upon its initiation, complications, methods of weaning, the presence of sepsis and multiple organ dysfunction syndrome as a cause of mortality, and finally the outcome of the patients as survival or demise. Indications for MV were categorized into: acute hypoxemic respiratory failure e.g. pneumonia, neuromuscular disease (NMD) subjects developing pneumonia presenting as acute carbon dioxide retention on top of a chronic disease e.g. myopathy, or acute neuropathy as Guillian Barré Syndrome, acute cardiovascular failure, encephalopathy and sepsis. The access to the airway to most of our subjects was through endotracheal intubation (ETT); orotracheal tubes and a few with nasotracheal tubes and tracheostomy. The modes of MV mostly used were assist control pressure controlled ventilation AC/PCV, assist control volume controlled ventilation $\mathrm{AC} / \mathrm{VCV}$, synchronized intermittent mandatory ventilation (SIMV) either volume or pressure limited, pressure support (PS), or SIMV with PS. Other parameters were set according to the patient's condition as $\mathrm{FIO}_{2}$, PEEP, PIP, and VT. Monitoring the subjects on MV was done with daily ABG at 8:00 am and on demand, and oxygen saturation was continuously recorded thorough pulse oximeter. Chest X-ray was ordered upon initiation of MV and on demand. Nursing care for subjects on MV was ordered as clearance of endotracheal tube secretions on demand through open-circuit suction catheter. Strategies to prevent VAP were adapted; hand hygiene, elevation of the head of the bed at an angle of 30 degrees, mouth wash with antiseptics, and changing ventilator circuits when visibly soiled or once weekly if the patient stayed longer. Nurse to patient ratio was 1 to 3 throughout day and night, and that is due to the financial limitation of the institute in the face of the sizable number of referred subjects from all over the country. Chest physiotherapy is done routinely by a nurse and frequently with an experienced physiotherapist once daily. Subjects were followed by a consultant intensivist rather than a respiratory therapist. Subject weaning was initiated after improving clinical condition, criteria of extubation were, $\mathrm{FIO}_{2}<0.4$, oxygenation index $<5$, rapid shallow breathing index (RSBI) is not more than 100 and no accessory work of breathing with ABG analysis reading; $\mathrm{pH}>7.3 \mathrm{PCO}_{2}$, is $35-50 \mathrm{mmHg}, \mathrm{PO}_{2}>60 \mathrm{mmHg}$. The occurrence of multiple organ system dysfunction was recorded as one of the causes of mortality.

\subsection{Definitions}

VAP was diagnosed in patients on ventilation for more than 48 hours with a new persistent infiltrate, on chest radiograph and at least 3 of the following; fever, leucopenia or leukocytosis, increased sputum production, rales, cough or worsening gas exchange (8). ARDS was defined according to the new Berlin definition (9). The spontaneous breathing trial (SBT) was defined as lasting from 0.5 to 2 hours performed with either, PSV $<10 \mathrm{~cm}$ $\mathrm{H}_{2} \mathrm{O}$ or a T-piece, or continuous positive airway pressure $<5 \mathrm{~cm} \mathrm{H}_{2} \mathrm{O}$, before extubation (10). Sepsis was defined according to international consensus conference on pediatric sepsis (11). Organ function status was evaluated according to the score described by Marshall et al. Five organ dysfunctions (lung, liver, kidney, hemodynamic and consciousness) were scored daily from no dysfunction to four points (severe dysfunction). Failure of organ function was considered at three or more points (12).

\subsection{Ethical considerations}

The aim and nature of the study was explained for each parent before inclusion. An informed written consent was obtained from parents or caregivers before enrolment. The study design conformed to the requirements of the latest revision of the Helsinki Declaration of Bioethics (13). The Scientific Research Committee of Pediatrics DepartmentFaculty of Medicine - Cairo University revised and approved the study design. 


\subsection{Statistical analysis}

Pre-coded data was entered into the IBM@ SPSS $\odot$ Statistics version 21 (IBM@ Corp., Armonk, NY, USA) for data analysis. Data was summarized using range, mean, standard deviation and median with interquartile range (IQR) for quantitative variables, and frequency and percentage for qualitative ones. Comparison between groups was performed using a Mann Whitney test for quantitative variables and Chi square with Fisher's exact test for qualitative ones. Multivariate logistic regression model was conducted to explore the significant predictors for PICU mortality with logarithmic transformation of the quantitative variables to assume normality. The $\mathrm{p}$-values less than 0.05 were considered statistically significant, and less than 0.01 were considered highly significant.

\section{Results}

In 2014, there were 893 patients admitted to two pediatric intensive care units. Of the 893 patients, 293 were ventilated with invasive MV, making the incidence of mechanically ventilated children $32.8 \%$. Clinical variables as age, sex, cause of mechanical ventilation whether surgical and medical, PRISM III score and duration of MV were presented in Table 1 as median and interquartile range. Reasons for initiation of mechanical ventilation were neurological causes in $114(38.9 \%)$ cases, respiratory causes in $71(24.23 \%)$ cases, cardiovascular causes in 58 $(19.8 \%)$ cases, safe airways in $34(11.6 \%)$ cases, and neuromuscular causes in $16(5.46 \%)$ cases. While the reasons for admission to intensive care were presented in Table 2: Neurological etiology in 101 cases, respiratory in 65 cases, cardiac in 54 cases, sepsis in 34 cases, NMD in 16 cases, renal in 6 cases, post-operative in 2 cases and other reasons in 15 cases. The access to airways were through endotracheal tubes in most cases, while 4 cases were tracheostomized (1.4\%). Regarding the modes used at the initiation of mechanical ventilation, SIMV + PS mode, $\mathrm{AC} / \mathrm{PCV}$ mode, $\mathrm{AC} / \mathrm{VCV}$, and PS were used in $49 \%, 29 \%, 13 \%$, and $9 \%$ of cases respectively. Duration of mechanical ventilation ranged from 2-90 days (median 9 and $\mathrm{IQR}=5-15$ ). $\mathrm{PaO}_{2} / \mathrm{FIO}_{2}$ ratio was classified into 3 groups $<200,200-300$ and $>300$. ARDS occurred in $26(8.9 \%)$ cases. Complications occurred in $117(39.9 \%)$ cases that is 29.5 per 1000 ventilation days, classified as the occurrence of VAP in $80(27.3 \%)(20.19 / 1000$ ventilation), pneumothorax 31 (10.6\%) (7.82/1000 ventilation days), atelectasis 13 (4.4\%) (3.28/ 1000 ventilation), and post extubation stridor (PES) 7 (2.4\%) (1.76/1000 ventilation). More than one complication occurred in 14/117 patients. Of the survived patients, eight were still not weaned till the study terminated. Methods of weaning were recorded in survived subjects, pressure support (PS) with CPAP in 115/154 (74.7\%) of cases, CPAP alone in 20 (12.9\%), t-tube in $11(7.1 \%)$ and unplanned accidental extubation in $8(5.1 \%)$. The occurrence of multiple organ dysfunction syndrome (MODS) was reported in 121 (41.3\%). Mortality occurred in 131/293 (44.7\%) of ventilated patients. Causes of mortality were sepsis in 53 cases (40.5\%), intractable heart failure in 33 (25.2\%), ARDS in 28 (21.4\%), brain death in $14(10.7 \%)$ and hepatic failure in $3(2.3 \%)$. Duration of mechanical ventilation was significantly longer in NMD (41.1 \pm 33.9 with median 28.5) (p 0.001), and with the occurrence of complications $(20.8 \pm 17.8$ with median 16) $(p<0.001)$. Expired patients stayed less on MV than survived ones $(p<0.001)$. Higher mortality rates were significantly related to higher PRISM III score $18.6 \pm 12.1$, cardiovascular cases, with sepsis, lower $\mathrm{PaO}_{2} / \mathrm{FIO}_{2}$ ratio $<200$ and 200-300, MODS, and with the occurrence of barotrauma and VAP. While lower mortality rates occurred with respiratory cases (Table 3). Multivariate logistic regression model was conducted to explore the significant predictors for PICU mortality. Both PRISM score and MV duration were subjected for logarithmic transformation to assume normality, $\mathrm{R}^{2}=(0.585-0.782)$, the only significant predictors were presence of complications, MODS, PRISM III on admission and MV duration (Table 4).

Table 1. Clinical characteristics of patients

\begin{tabular}{|l|l|l|}
\hline \multicolumn{2}{|l|}{ Variable } & \\
\hline \multirow{4}{*}{ Age } & Age (in months, median and IQR*) & $1-144(8,5-36)$ \\
\cline { 2 - 3 } & Less than 1 year; n (\%) & $135(52.2 \%)$ \\
\cline { 2 - 3 } & 1-6 years; (\%) & $107(36.5 \%)$ \\
\cline { 2 - 3 } & 6-12 years; (\%) & $33(11.3 \%)$ \\
\hline \multirow{5}{*}{ Sex } & Males, n (\%) & $162(55.3 \%)$ \\
\cline { 2 - 3 } & Females; n (\%) & $131(44.7 \%)$ \\
\cline { 2 - 3 } & PRISM III (median, IQR) & $10(6-20)$ \\
\hline \multirow{5}{*}{ Cause of admission } & Medical n (\%) & $269(91.8 \%)$ \\
\cline { 2 - 3 } & Surgical n (\%) & $24(8.2 \%)$ \\
\cline { 2 - 3 } & MV $\uparrow$ duration (median in days and IQR) & $9(5.0-15)$ \\
\hline
\end{tabular}

* interquartile range; $\uparrow \mathrm{MV}$ mechanical ventilation 
Table 2. Reasons for admission to intensive care

\begin{tabular}{|c|c|c|c|c|}
\hline Reason for admission & Sub classification & $\mathrm{n}$ & Subtotal \% & Total $\%$ \\
\hline \multirow{11}{*}{$\begin{array}{l}\text { Neurological } \\
(n=101)\end{array}$} & Coma & 21 & 20.8 & 7.1 \\
\hline & Encephalitis & 19 & 18.8 & 6.4 \\
\hline & Status epilepticus & 17 & 16.8 & 5.7 \\
\hline & $\mathrm{ICH}^{*}$ & 12 & 11.9 & 4.1 \\
\hline & Apnea & 9 & 8.9 & 3.0 \\
\hline & Stroke & 6 & 5.9 & 2.0 \\
\hline & Obstructed VP† shunt & 5 & 5.0 & 1.7 \\
\hline & Brain tumor & 3 & 3.0 & 1.0 \\
\hline & IEM + & 4 & 4.0 & 1.4 \\
\hline & TBI§ & 3 & 3.0 & 1.0 \\
\hline & Brain abscess & 2 & 2.0 & 0.7 \\
\hline \multirow{4}{*}{$\begin{array}{l}\text { Respiratory } \\
(n=65)\end{array}$} & Pneumonia & 45 & 69.2 & 15.4 \\
\hline & Bronchiolitis & 15 & 23.1 & 5.1 \\
\hline & FB\| inhalation & 3 & 4.6 & 1.0 \\
\hline & Bronchial asthma & 2 & 3.1 & 0.7 \\
\hline \multirow{3}{*}{$\begin{array}{l}\text { Cardiac } \\
(n=54)\end{array}$} & Shock & 21 & 38.9 & 7.2 \\
\hline & CHD & 18 & 33.3 & 6.1 \\
\hline & Cardiomyopathy & 15 & 27.8 & 5.1 \\
\hline Sepsis $(n=34)$ & Sepsis & 34 & 100.0 & 11.6 \\
\hline \multirow{4}{*}{$\begin{array}{l}\text { NMD } \\
(n=16)\end{array}$} & Spinal muscle atrophy & 8 & 50.0 & 2.7 \\
\hline & Congenital myopathy & 4 & 25.0 & 1.4 \\
\hline & $* * \mathrm{GBS}$ & 2 & 12.5 & 0.7 \\
\hline & Neiman pick disease & 2 & 12.5 & 0.7 \\
\hline Renal $(n=6)$ & Renal failure & 6 & 100.0 & 2.0 \\
\hline Post-operative $(n=2)$ & Post-operative & 2 & 100.0 & 0.7 \\
\hline \multirow{3}{*}{$\begin{array}{l}\text { Others } \\
(n=15)\end{array}$} & Toxic & 8 & 53.3 & 2.7 \\
\hline & Hepatic & 5 & 33.3 & 1.7 \\
\hline & Rheumatologic & 2 & 13.3 & 0.7 \\
\hline
\end{tabular}

*ICH: intracranial haemorrhage, $\dagger \mathrm{VP}$ : ventriculoperitoneal, $\$$ IEM: inborn error of metabolism, §TBI: traumatic brain injury, || FB: foreign body, $\uparrow$ CHD: congenital heart disease, **GBS: Guillian Barré Syndrome

Table 3. Relationship of outcome to various characteristics

\begin{tabular}{|c|c|c|c|c|c|c|}
\hline \multirow{2}{*}{\multicolumn{2}{|c|}{ Variable }} & \multicolumn{4}{|c|}{ Outcome } & \multirow{3}{*}{$\begin{array}{l}p- \\
\text { value* } \\
0.3\end{array}$} \\
\hline & & \multicolumn{2}{|c|}{$\begin{array}{l}\text { Non-survivors } \\
(\mathrm{n}=131)\end{array}$} & \multicolumn{2}{|c|}{$\begin{array}{l}\text { Survivors } \\
(\mathrm{n}=162)\end{array}$} & \\
\hline \multirow[t]{2}{*}{ Age (months) } & Mean \pm SD & \multicolumn{2}{|c|}{$28.0 \pm 35.2$} & \multicolumn{2}{|c|}{$26.5 \pm 33.8$} & \\
\hline & Median & \multicolumn{2}{|l|}{8.0} & \multicolumn{2}{|l|}{9.0} & \\
\hline \multirow[t]{3}{*}{ Age groups $n(\%)$} & $<1$ year & 71 & 54.2 & 82 & 50.6 & 0.6 \\
\hline & $1-6$ years & 44 & 33.6 & 63 & 38.9 & 0.4 \\
\hline & $>6$ years & 16 & 12.2 & 17 & 10.5 & 0.7 \\
\hline \multirow[t]{2}{*}{ Sex n $(\%)$} & Male & 69 & 52.7 & 93 & 57.4 & 0.5 \\
\hline & Female & 62 & 47.3 & 69 & 42.6 & \\
\hline \multirow[t]{2}{*}{ PRISM III on admission } & Mean \pm SD & \multicolumn{2}{|c|}{$23.7 \pm 11.6$} & \multicolumn{2}{|c|}{$8.2 \pm 3.9$} & $<0.001$ \\
\hline & Median & \multicolumn{2}{|c|}{20.0} & \multicolumn{2}{|l|}{8.0} & \\
\hline \multirow[t]{2}{*}{ Cause n (\%) } & Medical & 118 & 90.1 & 151 & 93.2 & 0.4 \\
\hline & Surgical & 13 & 9.9 & 11 & 6.8 & \\
\hline \multirow[t]{5}{*}{ Reason for admission $n, \%$} & Neurological & 40 & 30.5 & 61 & 37.7 & 0.2 \\
\hline & Respiratory & 19 & 14.5 & 46 & 28.4 & 0.005 \\
\hline & Cardiac & 33 & 25.2 & 21 & 13.0 & 0.010 \\
\hline & Sepsis & 24 & 18.3 & 10 & 6.2 & 0.002 \\
\hline & $\begin{array}{l}\text { Neuromuscular } \\
\text { disease }\end{array}$ & 4 & 3.1 & 12 & 7.4 & 0.1 \\
\hline
\end{tabular}


http://www.ephysician.ir

\begin{tabular}{|c|c|c|c|c|c|c|}
\hline & Renal & 4 & 3.1 & 2 & 1.2 & 0.4 \\
\hline & Post-operative & 0 & 0.0 & 2 & 1.2 & 0.5 \\
\hline & Others & 7 & 5.3 & 8 & 4.9 & 1.0 \\
\hline \multirow{5}{*}{$\begin{array}{l}\text { Reason for initiation of ventilation } \\
n, \%\end{array}$} & Neurologic & 47 & 35.9 & 67 & 41.4 & 0.4 \\
\hline & Respiratory failure & 19 & 14.5 & 52 & 32.1 & 0.001 \\
\hline & $\begin{array}{l}\text { Cardiovascular } \\
\text { failure }\end{array}$ & 37 & 28.2 & 21 & 13.0 & 0.002 \\
\hline & Sepsis & 24 & 18.3 & 10 & 6.2 & 0.002 \\
\hline & Neuromuscular & 4 & 3.1 & 12 & 7.4 & 0.1 \\
\hline \multirow[t]{3}{*}{$\mathrm{FIO}_{2} / \mathrm{PaO}_{2} \mathrm{n}(\%)$} & $<200$ & 59 & 45.0 & 51 & 31.5 & 0.02 \\
\hline & $200-300$ & 38 & 29.0 & 78 & 48.1 & 0.001 \\
\hline & $>300$ & 34 & 26.0 & 33 & 20.4 & 0.3 \\
\hline \multirow[t]{2}{*}{ ARDS n, $\%$} & Yes & 19 & 14.5 & 7 & 4.3 & 0.003 \\
\hline & No & 112 & 85.5 & 155 & 95.7 & \\
\hline \multirow[t]{2}{*}{ Airways n, \% } & Endotracheal tube & 131 & 100.0 & 158 & 97.5 & 0.1 \\
\hline & Tracheostomy & 0 & 0.0 & 4 & 2.5 & \\
\hline \multirow{2}{*}{$\begin{array}{l}\text { Mechanical ventilation duration } \mathrm{n} \text {, } \\
\%\end{array}$} & Mean \pm SD & \multicolumn{2}{|c|}{$8.5 \pm 6.9$} & \multicolumn{2}{|c|}{$17.5 \pm 19.5$} & $<0.001$ \\
\hline & Median & \multicolumn{2}{|l|}{7.0} & \multicolumn{2}{|c|}{10.0} & \\
\hline \multirow[t]{2}{*}{ Complications n, \% } & Yes & 64 & 48.9 & 53 & 32.7 & 0.006 \\
\hline & No & 67 & 51.1 & 109 & 67.3 & \\
\hline \multirow[t]{2}{*}{$\mathrm{VAP} \uparrow(\%)$} & Yes & 47 & 35.9 & 33 & 20.4 & 0.004 \\
\hline & No & 84 & 64.1 & 129 & 79.6 & \\
\hline \multirow[t]{2}{*}{ Pneumothorax n, \% } & Yes & 19 & 14.5 & 12 & 7.4 & 0.06 \\
\hline & No & 112 & 85.5 & 150 & 92.6 & \\
\hline \multirow[t]{2}{*}{ Atelectasis n, $\%$} & Yes & 3 & 2.3 & 10 & 6.2 & 0.2 \\
\hline & No & 128 & 97.7 & 152 & 93.8 & \\
\hline \multirow[t]{2}{*}{ PES } & Yes & 3 & 2.3 & 4 & 2.5 & 1.0 \\
\hline & No & 128 & 97.7 & 158 & 97.5 & \\
\hline \multirow[t]{2}{*}{ MODS§ n, \% } & Yes & 98 & 74.8 & 23 & 14.2 & $<0.001$ \\
\hline & No & 33 & 25.2 & 139 & 85.8 & \\
\hline
\end{tabular}

${ }^{*} p$ value less than 0.05 is significant, $\dagger$ VAP: ventilator- associated pneumonia, $\ddagger$ PES: post extubation stridor, $\S$

MODS: multiple organ dysfunction syndrome

Table 4. Multivariate logistic regression model

\begin{tabular}{|l|l|l|l|l|}
\hline Variables & $p$-value & OR & \multicolumn{2}{|c|}{$95 \%$ CI of OR } \\
\hline Female sex & 0.068 & 2.365 & 0.939 & 5.956 \\
\hline Cardiovascular as a reason for MV initiation & 0.891 & 0.924 & 0.298 & 2.863 \\
\hline Respiratory as a reason for MV initiation & 0.149 & 0.410 & 0.122 & 1.377 \\
\hline Sepsis as a reason for MV initiation & 0.118 & 0.277 & 0.055 & 1.387 \\
\hline Presence of complications & 0.002 & 4.823 & 1.761 & 13.206 \\
\hline MODS & $<0.001$ & 8.711 & 3.077 & 24.660 \\
\hline PRISM III on admission & $<0.001$ & 1.406 & 1.260 & 1.568 \\
\hline MV duration & 0.008 & 0.909 & 0.846 & 0.976 \\
\hline
\end{tabular}

\section{Discussion}

This study is the first study to address the practice of MV in pediatric intensive care in an Egyptian university hospital. Studies were performed elsewhere; in USA, Canada, Italy and other countries, to investigate the use of MV in their PICUs $(2,3,5,17)$, however we have different subjects' characteristics and different risk factors added to the limited financial resources. The majority of our patients are of low socioeconomic backgrounds; in addition, they are referred to our center in a rather late stage of diseases that adds to the complexity of their disease. The incidence of utilizing mechanical ventilation in our units is $32.8 \%$. Other published studies reported incidence rate of MV utilization $35 \%-64 \%(4,6,7)$. In the present study, neurologic causes were the most frequent reason of ventilation 144 (38.9\%). Other studies reported a high incidence of neurologic causes for MV; 32 and 36\% in less developed countries $(1,3)$. These results contrasted with other published studies on pediatric subjects, as the most common 
indications were respiratory causes that represented $60 \%-75 \%$ of ventilated subjects $(4,6,7,14-16)$. This can be explained by being a tertiary care hospital, most cases referred to us are severe and complicated neurologic cases. Most respiratory cases are treated at their local hospitals. Also, the warm climate all year round except January and February months which are cold winter months, explains the low incidence of viral respiratory infections. The most common mode of ventilation used initially was pressure control with SIMV and PS (49\% of cases). Harel et al. reported that the preferred mode for initiating the MV in infants and children was SIMV with a percentage ranging from $65 \%$ to $82 \%$, followed by PCV (2-17\%) (17). MV use is not without complication. It can no longer be viewed simply as a harmless modality deployed to support the subject while disease-specific treatments are used to treat the underlying pathology (18). Those complications may prolong the duration of MV itself, or the overall duration of hospitalization, or increase subject mortality (19). Complication occurred in 117 (39.9\%) cases, subjects with VAP had the highest incidence with 80 cases (27.3\%) accounting for 20.19 per 1000 ventilation days. These results were similar to the results obtained by Principi and co-workers who found a complication rate of $40 \%$ in mechanically ventilated children; however, atelectasis was the most common complication found in $16.7 \%$ of cases in the Principi study (19). Unfortunately, the incidence of VAP in our units is still very high, although we are trying to endorse VAP bundle, still there is a missing link with our low-staffed units and the absence of infection control personnel monitoring during night shifts.

Ratio of VAP was high in our study compared to the incidence of VAP in high-income countries; (2.1-5.5 per 1,000 days) according to NNIS and INNIC surveillance data (20). While Elward and co-workers recorded VAP incidence of 11.6/1000 ventilator days (21). In children SBTs in pediatrics have been shown to be feasible and to have a high sensitivity for predicting extubation success (22). SBT with pressure support mode of weaning is the preferred method of weaning in our practice, used in 115/154 (74.7\%) of survived subjects. ARDS came in third place as a cause of mortality occurring in $28(21.4 \%)$, which was lower than other studies. ARDS, as a cause of mortality in MV children was found to be $32 \%-36.5 \%$ in two European studies $(23,24)$, while this ratio was doubled in an Asian study to reach $60 \%$ (25). We have found mortality rate to be $(44.7 \%)$ in our study and this mortality was significantly higher with higher PRISM III, MODS, cardiovascular cases, barotraumas, occurrence of VAP, and ARDS, while respiratory cases had the lowest mortality. According to the age groups, infants less than 1 year had the higher mortality than older age groups; $71 / 131(54.2 \%)$, however it was not statistically significant $(\mathrm{p}=0.6)$. Multivariate logistic regression model was conducted, $R^{2}=(0.393-0.526)$, the only significant predictors were presence of MODS, PRISM III score. Reported mortality of children on MV in developed countries were $1.6-15 \%$ $(4,5,7,26)$, while mortality rate was higher in less developed countries $30-3 \%-58.3 \%(3,17)$. Prognosis of mechanically ventilated children was reported to be related to high PRISM score, and the presence of MODS in other studies $(26,27)$. Regarding the limitation of the study, the study did not include arterial blood gases (ABGs) parameters, or ventilator setting changes used in the study according to ABGs.

\section{Conclusions}

MV is frequently deployed in PICU practice. Most children are ventilated due to neurologic causes. The most common mode of ventilation is pressure control with SIMV and PS, while the weaning mode of choice is PS with CPAP. Mortality rate was high and correlated with higher PRISM III score and MODS. We believe that this study described our employment of ventilation in Egypt adequately in one of its biggest pediatric hospitals, and that pediatric intensivists still cling to conventional modes of ventilation, and decline to use newer modes. We recommend extensive training of the physicians and nurses to decrease complications rate.

\section{Acknowledgments:}

The authors are grateful to the Cairo University Pediatric Hospital for supporting this study.

\section{Conflict of Interest:}

There is no conflict of interest to be declared.

Authors' contributions:

All authors contributed to this project and article equally. All authors read and approved the final manuscript.

\section{References:}

1) Medjo B, Vunjak N, Atanaskovic-Markovic M, Rsovac S, Nikolic D, Kalanj J, et al. Indications and complications of mechanical ventilation in pediatric intensive care unit patients. Arch Dis Child. 2008; 93 : 491. 
2) Vijayakumary T, De Silva JRS, Sarathchandra J, Kumarendran B. Prospective study of ventilated patients in the pediatric medical intensive care unit of Lady Ridgeway Hospital. Sri Lanka Journal of Child Health. 2012; 41(3): 114-7. doi: 10.4038/sljch.v41i3.4598.

3) Mukhtar B, Siddiqui NR, Haque A. Clinical characteristics and immediate-outcome of children mechanically ventilated in PICU of Pakistan. Pak J Med Sci. 2014; 30(5): 927-30. PMID: 25225500, PMCID: PMC4163205.

4) Wolfler A, Calderoni E, Ottonello G, Conti G, Baroncini S, Santuz P, et al. Daily practice of mechanical ventilation in Italian pediatric intensive care units: a prospective survey. Pediatr Crit Care Med. 2011; 12(2): 141-6. doi: 10.1097/PCC.0b013e3181dbaeb3. PMID: 20351615.

5) Farias JA, Fernández A, Monteverde E, Flores JC, Baltodano A, Menchaca A, et al. Mechanical ventilation in pediatric intensive care units during the season for acute lower respiratory infection: a multicenter study. Pediatr Crit Care Med. 2012; 13(2): 158-64. doi: 10.1097/PCC.0b013e3182257b82. PMID: 21725275.

6) Farias JA, Frutos F, Esteban A, Flores JC, Retta A, Baltodano A, et al. What is the daily practice of mechanical ventilation in pediatric intensive care units? A multicenter study. Intensive Care Med. 2004; 30(5): 918-25. doi: 10.1007/s00134-004-2225-5. PMID: 15029473.

7) Randolph AG, Meert KL, O'Neil ME, Hanson JH, Luckett PM, Arnold JH, et al. The feasibility of conducting clinical trials in infants and children with acute respiratory failure. Am J Respir Crit Care Med. 2003; 167(10): 1334-40. doi: 10.1164/rccm.200210-1175OC. PMID: 12615617.

8) CDC. NNIS criteria for determining nosocomial pneumonia. Atlanta, GA: Department of Health and Human Services, CDC; 2003.

9) ARDS Definition Task Force, Ranieri VM, Rubenfeld GD, Thompson BT, Ferguson ND, Caldwell E, et al. Acute respiratory distress syndrome: the Berlin Definition. JAMA. 2012; 307(23): 2526-33. PMID: 22797452.

10) Farias JA, Retta A, Alía I, Olazarri F, Esteban A, Golubicki A, et al. A comparison of two methods to perform a breathing trial before extubation in pediatric intensive care patients. Intensive Care Med. 2001; 27(10): 1649-54. doi: 10.1007/s001340101035. PMID: 11685307.

11) Goldstein B, Giroir B, Randolph A. International Consensus Conference on Pediatric Sepsis International pediatric sepsis consensus conference: definitions for sepsis and organ dysfunction in pediatrics. Pediatr Crit Care Med. 2005; 6(1): 2-8. doi: 10.1097/01.PCC.0000149131.72248.E6. PMID: 15636651.

12) Marshall JC, Cook DJ, Christou NV, Bernard GR, Sprung CL, Sibbald WJ. Multiple organ dysfunction score: a reliable descriptor of a complex clinical outcome. Crit Care Med. 1995; 23(10): 1638-52. doi: 10.1097/00003246-199510000-00007. PMID: 7587228.

13) World Medical Association Declaration of Helsinki. Ethical Principles for Medical Research Involving Human Subjects. Revised by the 59th WMA General Assembly. Available from: http://www.wma.net/en/30publications/10policies/b3.

14) Kendirli T, Kavaz A, Yalaki Z, Ozturk Hismi B, Derelli E, Ince E. Mechanical ventilation in children. Turk J Pediatr. 2006; 48(4): 323-7.

15) Khemani RG, Markovitz BP, Curley MA. Characteristics of Children Intubated and Mechanically Ventilated in 16 PICU. Chest. 2009; 136(3): 765-71. doi: 10.1378/chest.09-0207. PMID: 19542258, PMCID: PMC2775993.

16) Silva DC, Shibata AR, Farias JA, Troster EJ. How is mechanical ventilation employed in a pediatric intensive care unit in Brazil? Clinics (Sao Paulo). 2009; 64(12): 1161-6. doi: 10.1590/S180759322009001200005. PMID: 20037703, PMCID: PMC2797584.

17) Harel Y, Niranjan V, Evans BJ. The current practice patterns of mechanical ventilation for respiratory failure in pediatric patients. Heart Lung. 1998; 27(4): 238-44. doi: 10.1016/S0147-9563(98)90035-8.

18) Rotta AT, Steinhorn DM. Conventional mechanical ventilation in pediatrics. Journal de Pediatria. 2007; 83(2): 100-8. doi: 10.2223/JPED.1617.

19) Principi T, Fraser DD, Morrison GC, Farsi SA, Carrelas JF, Maurice EA, et al. Complications of Mechanical Ventilation in the Pediatric Population. Pediatr Pulmonol. 2011; 46(5): 452-7. doi: 10.1002/ppul.21389. PMID: 21194139.

20) Rosenthal VD, Maki DG, Jamulitrat S, Medeiros EA, Todi SK, Gomez DY, et al. International Nosocomial Infection Control Consortium (INICC) report, data summary for 2003-2008, issued June 2009. Am J Infect Control. 2009; 38(2): 95-104. doi: 10.1016/j.ajic.2009.12.004. PMID: 20176284.

21) Elward AM, Warren DK, Fraser VJ. Ventilator-associated pneumonia in pediatric intensive care unit patients: risk factors and outcomes. Pediatrics. 2002; 109(5): 758-64. doi: 10.1542/peds.109.5.758. PMID: 11986433. 
22) Chavez A, dela Cruz R, Zaritsky A. Spontaneous breathing trial predicts successful extubation in infants and children. Pediatr Crit Care Med. 2006; 7(4): 324-8. doi: 10.1097/01.PCC.0000225001.92994.29. PMID: 16738500.

23) Peters MJ, Tasker RC, Kiff KM, Yates R, Hatch D. Acute hypoxemic respiratory failure in children: case mix and the utility of respiratory severity indices. Intensive Care Med. 1998; 24(7): 699-705. doi: 10.1007/s001340050647. PMID: 9722040.

24) Bindl L, Betancort M, Demirakca S, Fedora M, Goldner M, Holzki, et al. ARDS database in children: data of 91 patients collected by a collaborative internet database.

25) Goh AY, Chan PW, Lum LC, Roziah M. Incidence of acute respiratory distress syndrome: a comparison of two definitions. Arch Dis Child. 1998; 79(3): 256-9. doi: 10.1136/adc.79.3.256. PMID: 9875023, PMCID: PMC1717687.

26) Farias JA, Frutos-Vivar F, Casado Flores J, Siaba A, Retta A, Fernández A, et al. Grupo Internacional de la Ventilación Mecánica en Niños. Factors associated with the prognosis of mechanically ventilated infants and children. An international study Med Intensiva. 2006; 30: 425-31. doi: 10.1016/S0210-5691(06)74565$\mathrm{X}$.

27) Dahlem P, van Aalderen WM, Hamaker ME, Dijkgraaf MG, Bos AP. Incidence and short-term outcome of acute lung injury in mechanically ventilated children. Eur Respir J. 2003; 22(6): 980-5. doi: 10.1183/09031936.03.00003303. PMID: 14680089. 